\title{
THE IMPORTANCE OF INTEGRATING MULTICULTURALISM IN TEACHING COMMUNITY INTERPRETING
}

\author{
Fitrotul Maulidiyah \\ Politeknik Negeri Malang, Jl. Soekarno Hatta No. 9 Malang, \\ Email : fitrotulmaulidiyah@polinema.ac.id
}

\begin{abstract}
Globalization and massive development in communication and information technology generates multiculturalism in the last few years. It enables people live their originality consciously and without authorization of the other cultures. In other words, multiculturalism is a cultural wealth for living together. Furthermore, people who have different cultures consider that it is necessary to find a way to have proper intercultural communication especially when they live together. Multiculturalism is considered compulsory for social diversity including its appearance and recognition. Moving from this thought, interpretation, a social phenomenon between different languages and cultures has an undeniable function especially for community interpretating. The function of community interpreting and intercultural communication is multifaceted. The community interpreter has to know the languages, the cultures they belong to, their social structures, world understandings and value judgments. Multiculturalism needs social and cultural diversity. Therefore, a community interpreter has to apply every culture's necessities equally besides the interpreting procedures. In multicultural societies formed by different cultures, community interpreting plays a pivotal role in order to live together peacefully towards common boundaries. Community interpreting has a mission on conciliation and adaptation of different cultures and values. Community interpreting helps social structures compromise in the sense of multiculturalism and recognize their cultural background. This study will examine the necessity of multiculturalism integration in the teaching of community interpreting which has become more important in recent days. This is intended for communities with diverse cultures to continue their harmonious coexistence and to maintain their presence in the content of multiculturalism.
\end{abstract}

Keywords: community interpreting, integration, multiculturalism

\section{INTRODUCTION}

\section{A. Background of the Study}

Different cultures, which have historically been forced to coexist in a social context for various reasons, have generally created different cultural 
and political structures. Yet, every society is still striving to preserve its own cultural authenticity. This creates a cultural and social diversity in which different cultures coexist. It is necessary to stay within a multicultural society structure in order to tolerate social diversity, to respect each other's cultural values and to sustain their existence.

Multiculturalism is the coexistence of a community of two or more different cultures. This means a society in which two or more languages are spoken. In communities where different cultures are spoken, it is impossible for the "translation" effect to be the case. Translation is an inter-communal agreement that persists its existence in the environments where different cultures come together. Translation, which is a transfer function between different cultures, has a social role to translator. It is expected that the translator who does translating to be multicultural and to know two cultures well.

While the translator is supposed to be multicultural, it is necessary to know the different social structures and anticipations from multicultural society life. The concept of "community interpretation", which is one of the interpreting types expected to be realized as content today, is on the agenda. Community interpreting services are a prerequisite for societies with cultural diversity to live together in peace in a multicultural social order. Community interpreting has the task of providing translation services to societies where they have different cultures and at the same time sharing their common values with each other and explaining the conditions of living in harmony.

Community interpreting is usually referred to as a special type of oral translation facilitating access to public services by mediating between service users and service providers who do not share the same language. Despite the fact that it is a rapidly growing field, especially in the countries with expanding foreign-based work force, we are witnessing a certain divergence in its perception. The variance is not only in a number of different names under which it can be found, such as public service interpreting (UK), cultural interpreting (Canada), liaison interpreting (Australia), contact interpreting (Scandinavia), dialogue interpreting, ad hoc, triangle, face-to-face, and bidirectional or bilateral interpreting (Gentile et al, 1996; Carr, 1997) but also in its scope. Although different interpretations of the term in most cases reflect different needs, traditions and local specifics, it is possible to define the generally accepted common features of the phenomenon.

Community interpreting is sometimes distinguished from other types of interpreting by the contexts in which it is employed. It is understood as a kind of interpreting that takes place in neighborhoods and community 
agencies and is performed by amateurs or unpaid volunteers, often perceived as non-professional interpreters. It is related to situations in which non-native speakers are aided by native speakers (but also non-native speakers) in their communication with the providers of various public services. The settings where communication takes place include hospitals and doctors' offices, attorneys' offices, social welfare and housing agencies, employment agencies, or police stations. It is obvious that the typical clients are mostly migrant workers and their families and members of specific ethnic groups in large cities.

Another characteristic feature of community interpreting is the degree of formality/informality in the interpreting activities. Instead of interpreting a speech to a large audience, a community interpreter works in a more interactive atmosphere, often with a dialogic structure. This approach stresses the dialogic setting regardless of the given situation, whether this is in hospitals, public service agencies or police department. Therefore, it is sometimes labelled as dialogue interpreting.

There is consensus in the literature that the community interpreter is required to be competent in the relevant languages and cultures (Jiang 2007) and in the communicative process of everyday and domain knowledge of an institutionalized communicative situation. The domain knowledge is often equated with terminological knowledge but recently has also included norms and conventions.

In this sense, community interpretation, which is a major contributor to the formation of a multicultural society, should help to contribute to the formation of a social transformation by raising the awareness of differences rather than emphasizing social differences. In addition to the task of ensuring communication between different cultures, community interpreting has the task of teaching the official language of the target country which will be the common language in the future.

In this sense, they also need to recognize the methods of language teaching. Nowadays, when different cultures can come together easily, and are to be together, community interpreters should also be provided with a multi- purpose education. For this reason, foreign language teaching, especially at an early age, should take place in curriculum. As it is known, foreign languages to be learned at an early age, the children are stripped of the prejudices against the foreigner and learn to tolerate the different and to respect the other. By making a comparison by this, it is also to realize its own values. The necessary importance should be given to the community interpreting parallel to the new society structures composed of different cultures. Community interpreters, who are well-equipped people who recognize many languages and cultures, will contribute to the maintenance 150 
of the continuity of multicultural societies and to the solution of all their distant problems without conflict.

\section{B. Literature Review Multiculturalism}

When the word "multiculturalism" is considered in terms of meaning, it is necessary to know from which word the culture word is derived and the word meaning. It is derived from the Latin word colere, which means to process the land, to drive the field, to plant it. The dictionary definition of the concept of culture today is the whole of the material and spiritual beings, values, and traditions that a human community (nation) transmits from generation to generation. Belief, idea, knowledge art, customs and traditions are all in the form of life and behavior (M.E.B, 1999). Each language reflects the logic and thought of the country in which it is spoken; culture reflects the values, traditions, unique human-community life, world understanding and beliefs of the nations in which they live. In this sense, multiculturalism is the coexistence of a community (nation) of two or more different cultures. Multiculturalism is a form of political organization, characterized by communities with different cultures enjoying coexistence without losing their self-culture and enjoying all the public services provided. According to Parekh (2001), it is one of the concepts that are used and popularized while trying to analyze and analyze the important part of big cultural problems.

It is also a form of diversity that emerges in the community and in certain organized communities and cultural groups that live according to their own cultural structures and practice systems. Multiculturalism offers many cultural privileges to societies that have to come together for various reasons together. Within the context of multiculturalism, cultural rights are exempt from exclusion measures, religious practices, language and special education. According to Doytcheva (2009), multiculturalism is a historical political program, intellectual debate and practical experience, based on the idea that modern democracies should recognize different cultures by reshaping their institutions and allowing them to improve and convey their differences.

The notion of multiculturalism was initially introduced in Canada in 1971 as part of Trudeau administration program in an attempt to provide equal opportunities for the national minorities and immigrants regardless of their backgrounds, including social status, political view, and ethnicity (Fleras \& Elliott, 2002; Guo, 2011). Parekh (2000) linked multiculturalism to a blend of various cultures through culture. In a similar vein, multiculturalism is the condition when individuals with different backgrounds such as culture, language and belief, stay side by side in the 
same area and respect each other's differences (Colombo, 2015). Within multiculturalism, the presence of diverse social structures, identities, and cultures is considered as the driving source of change in society. Accepting diversity, cultivating unity, and making it as a routine, can be realized by practicing ME (Fowers \& Davidov, 2006). Multicultural Education identifies certain principles, values, and practices, which are arguably compatible with almost every aspect of work and life (Shannon-Baker, 2018). Therefore, Singh (1984) considers ME a vital factor in the curriculum. His study suggests that if one sees $\mathrm{ME}$ as an initial understanding of a blend of diverse cultures, $\mathrm{ME}$ could be then integrated in every curriculum (see also, Brent, 1982).

\section{Community Interpreting}

Interpretation is as old as human history. As long as there are different languages spoken on the world, it will remain an indispensable activity in order to eliminate linguistic obstacles and to provide healthy communication between people. In the century that we are living, multicultural societies are formed for various reasons.

Community interpreting is sometimes distinguished from other types of interpreting by the contexts in which it is employed. It is understood as a kind of interpreting that takes place in neighborhoods and community agencies and is performed by amateurs or unpaid volunteers, often perceived as non-professional interpreters. It is related to situations in which non-native speakers are aided by native speakers (but also non-native speakers) in their communication with the providers of various public services. The settings where communication takes place include hospitals and doctors' offices, attorneys' offices, social welfare and housing agencies, employment agencies, or police stations. It is obvious that the typical clients are mostly migrant workers and their families and members of specific ethnic groups in large cities.

As a consequence of the lack of a conceptual framework, opinions on the specific forms of community interpreting significantly vary from author to author, from country to country. The most controversial issue is whether community interpreting should also include such specific fields as court interpreting or conference interpreting. Roberts (2002) argues that community interpreting differs from court interpreting and conference interpreting. In community interpreting, there are (a) different objectives, (b) different types of parties involved, (c) different number of parties, (d) different discourse used, (e) different mode of interpreting, and (f) differences in the directionality of interpreting. Several authors include court interpreting into community interpreting (Mikkelson 1996b). Typical community interpreters, however, have not only a different role compared to 
court interpreters but also a different degree of responsibility. Therefore, as ad hoc service providers they are often related to non-professional interpreting services rendered by whoever is immediately available such as medical hospital staff, family members (including children) or even other patients. Court interpreters, on the other hand, are in most countries specialized professionals offering assistance not only to defense or prosecution but they are also active prior to the case. The fulfilment of this role requires an understanding by the interpreter of the complexities of the task to be performed and the fundamental ethical principles and standards prescribed by judicial authorities. In the case of court interpreting, the principle of neutrality and detachment is taken for granted. Accuracy, impartiality, confidentiality, proficiency and demeanor belong to the major quality requirements for court interpreters.

With regard to the above-mentioned characteristics of community interpreting, introducing specialized training courses especially for bilingual individuals, including those representing linguistic minorities may be a challenge for institutions involved in translation and interpretation training. Such on-purpose-designed training courses could have the following major goals: (1) to ensure a high level of expression accuracy in the interpreter's working languages; (2) to develop awareness of potential cross-cultural differences in specific public services; (3) to develop the relevant skills for consecutive interpreting, including note-taking and message retention techniques; and (4) to ensure the candidate's commitment to a professional code of ethics. The overall aim of such training courses would be to develop community interpreting competence and thus to contribute to its professionalization and to make sure that individuals and organizations providing interpreting services have the appropriate skills and knowledge to provide high quality effective services for their clients.

In short, community interpreters have a great responsibility to maintain community integrity and permanence. It is important to tell different ethnicities and establish a dialectic between them. They bring multiculturalism, cultural and social wealth together. It is possible to live in the common boundaries of this richness, to respect the differences. In this context, multiculturalism is defined as: multiculturalism, based on the fact that individuals and groups forming a society come from different backgrounds in terms of language, religion, race, history, geography, is a single political unit and communities living within common boundaries.

The evaluation of the translation with its social dimension has recently come to an end. It has been proven through the experience of social transformations and changes through translation. For this reason, translation is closely related to social events and sociology. Moreover, the great role of 
translation in intercultural communication is an undeniable fact. Translation is a matter of cultural context rather than the context of text-to-translator, and should be evaluated within this system. Translation has now undertaken a task in which the source text conveys the cultural facts to the other side as well as responds to expectations in the cultural context of the target society. Moving from this thought; community interpreting is being used to meet different social expectations in the solution of the problems and cooperations brought about by today's international social and cultural events.

Nida (1964) stated that translation is a social and cultural process rather than a means of linguistic transmission. In keeping with this definition, the community interpreters who undertake the task have a social role, such as mutual recognition of the socio-cultural structure of the community in which both languages are spoken. With the thought that the language of the society in which the languages are spoken reflects the culture, logic and original expression of the culture: the culture structure, which is the language, is also the behavior of the individuals belonging to the society. Community interpreters are the cultural mediators. Because of this, they provide cross-cultural dialogue, helping communities with different tongues to tolerate and prejudge the values of their foreign country. In addition to this, they provide a means to compare with other cultures and to make sure that their culture is aware of their societies. They make it possible for them to maintain their harmony and keep their cultural values in mind. It is also known that it is related to different scientific disciplines other than translating work, going even further than translation work. According to Gürçağlar (2009), the studies in the field of translational science should be very close to other disciplines in terms of methodology and they should form an examination field and think that translationoriented contribution will be very great. The data obtained indicate that translation is not only an activity related to literature, information production and publishing, but also a means of building nation, a trigger, medium, or a form of social outsourcing of processes of social transformation (Ar1 2014).

It is used in the intercultural communication needs arising from the bureaucratic processes encountered by immigrants in the social life in the heavily immigrant countries (such as Scandinavian countries, European countries like Germany, France, Netherlands, USA, Canada and Australia) where different languages are spoken and different cultures meet. In fact, in multilingual and cultured societies it is precisely the linguistic communication that is the ultimate aim of translation. In this sense, Eruz (2010) states that it is the formation of primary purpose in communication of translation in multicultural societies. Interpreters are responsible for 
communicating with the public authorities through the public when the language is different from the official language. In multilingual societies, however, there is a great deal of responsibility for this translation support as well as for bilingual interpreters of community interpreters to learn the official language of that country. The point to note here is that different language speakers should not forget their own language and culture.

Community interpreters who are expected to be experts in language and social cohesion need to know well the language teaching methods to be applied in language teaching. In this sense, it is important for the community interpreters to be good educators in addition to being the culture and language mediator. From this point of view, it seems possible that translators who have been trained in a multi-purpose interpreter to be competent in their own fields.

\section{DISCUSSION}

\section{Reasons for Multicultural Education in Indonesia}

As emphasized above, effective method to prevent conflicts between ethnics, nations, is multicultural education. Along with epoch development affected by globalization, many social-cultural crises occurred in society. For example, degradation of appreciation and compliance with law, ethics, morals, and social politeness. Narcotics and other social disorders distributed widely. Therefore, multicultural education is effective method to build awareness in multicultural society. Orderliness in social-cultural life can be realized through multicultural education.

There are some opinions of experts concerning multicultural education. Andersen and Cusher (1994) stated that multicultural education is education concerning diversities of cultures. Banks (1993) defined multicultural education as education for people of color. It means that multicultural education wants to explore difference as inevitability. Where, in such condition, we can accept difference in full tolerance. Multicultural education is response to school population diversity development, as rights equality demand for each of groups. It can mean that multicultural education is education consisting of all students without discriminating groups, such as, gender, ethnic, race, culture, social stratum, and region. Multicultural education is defined as education with cultural diversity in responding to demographic change and cultural setting of certain society or even the whole world.

A number of multicultural-based education definitions are associated with certain disciplines, such as, anthropological, social, psychological educations, etc. Classical definition emphasizes on multicultural-based education essence as perspective experienced by each individual in complex 
and diverse human encounters culturally. This definition also reflects importance of culture, race, gender, ethnicity, regions, social and economic status, and exclusions in education process. Other definition means that multiculturalism-based education is a vision on education which should be feasible and proper for all students. This education prepares students for their citizenship in plural and associated cultural and language community, illustrates social, economic and politic reality widely and systematically as to affect everything occurring inside and outside schools, re-widen rejected optima; education. It also discusses creation of educational institutions providing dynamic learning setting, reflecting equality inspiration, similarity, and excellence.

Although these definitions are different, but all of them underline that education must be based on multiculturalism. Indonesia consisting of diverse different people such different regions, ethnics, races, cultures, customs, languages, etc. make society a plural one. Such diverse life becomes challenge to integrate Indonesian nation into one force, which may appreciate society diversity and difference. It can be done by multicultural education implanted in children through learning in schools and homes. A teacher is responsible for giving education to students and assisted by parents in seeing difference occurring in their daily life. However, multicultural education is not only limited to school age children but also to state society in general through agenda or seminars increasing importance of tolerance in diversity make society accept that they live in difference and diversity.

According to specialists, Indonesia has three great challenges in implementing multicultural education, namely: (1) regions, ethnics and traditions. Actually, regions are vital association in Indonesian life as a nation. After all, it will be destructive to harmonic society force when it is used as politic weapon or economic facilities for individual or groups. In this case, regions are associated with life ethnics and traditions of a society. Each individual has used religious principles to guide him/her in societal life, but to not share knowledge from religious faith to others. It can only be done through multicultural education to achieve goal and one's principles in appreciating regions; (2) faith, plural society always considers risks of various differences. Risks of suspect/fear or unbelief in others can also occur when there is no communication in plural society; (3) tolerance, tolerance is highest form, indicating that we can gain belief. Tolerance can be reality when we assume that there is a difference. Belief is an issue which can be changed. So that, tolerance must not always maintain belief. Achievement of goal as Indonesian human who may be democratic and living in Indonesia needs multicultural education (Munib, 2009). 
Challenge in Indonesian educational world now is very heavy and complex. So, efforts to anticipate must be serious and followed by concrete solution. If not responded seriously in especially educational field responsible for quality human resources, the students will lose direction and forget their cultural origins alone. Multicultural education as basis to develop curriculum becomes very important if, in giving a number of materials and contents of learning, must be mastered by students in certain measure and level. State prioritizing multicultural education and implementing it according to epoch demand, will prevent all types of fundamentalisms, radicalisms, separatisms, race, ethnic, religious discriminations, etc.

\section{Reasons for Formation of Multiculturalism and Community Interpreting}

Community interpreting has the task of helping people who have left their countries through migration and benefiting from social services in their countries of origin. Both communities are helping to define the cultures and the harmony of different cultures. Community Interpreters have a preventive role for conflicts that may arise in the life cycle of the differences, the other way of thinking. The rapid development of communication technology has increased the influence of the media, which is the cause of multiculturalism. The fact that communities with diverse cultures share common values through media not only allows the emergence of cultural riches but also causes them to accept and tolerate different ones. Media activities are very effective in creating common modes of behavior for different societies. Efficient media is a tool that will make a great contribution to living together without destroying the differences. Community interpreters will also use this influence of the media to help multicultural societies live smoothly in the recipient countries.

Community interpreters will be engaged in understanding the publications that will create a common life image for social life through media communication tools. For the continuity of multicultural society life, community interpreters need to know and apply language teaching methods, especially at an early age. Because the official language of the immigrant country that is to be used in multicultural society is important in terms of the common communication language. In addition, every community should translate interpreters of communities by "localizing" them. This different value is important in terms of acceptance of judgments.

Parallel to rapid developments in the world, economic and social changes have become a matter of mobility. The structure of the capitalist system has caused the expansion of business areas in different countries of 
the world. An international economic structure has emerged under the name of globalization. Political power, having this economic power, is the cause of the international mobility of the masses. All transnational mobility brings with it a cultural structuring. This is what happens in a multicultural social life that is caused by globalization. While globalization is integrated in economic sense, it also anticipates integration in social life. This is the gathering and living of different cultures. Community interpretation has assumed the role of a guarantor of a "social contract" among societies seeking to live their own cultures. In this sense, community interpreters must make an effort to avoid economic, political, or cultural conflicts.

At the same time, they are contributing as a well-equipped person who knows the cultural values and thought rationale of co-living societies in solving the problems that globalization brings to their barbers. While community interpreters help with the need to benefit from public services, they also need to actively participate in issues that arise in the public domain. Even if there are different cultural societies, "common utility" is necessary for living together. Multilingual, multicultural community interpreters, as a mediator of social cohesion, are indispensable elements of a multicultural society. Common criteria should be set for the training of interpreters who will serve the collective all over the world. They should be able to provide the necessary training to meet these conditions. For the person who will be the community translator, studies should be carried out to define the cultural and social structure of the society by ensuring that the countries where the language of which they are spoken are kept for a certain period of time.

\section{CONCLUSION}

Each community has the right to experience their own cultural background and experience. But nowadays no society is allowed to remain unaffected by different cultures within their borders. All societies benefit from communication technology, which is a necessity for the time being, to the utmost extent, and therefore recognize cultural products of different societies.

When included in these factors, it is impossible to keep the societies away from the cultural differences that persist in their existence on the world, as the globalization which brings down the world and which brings about a lot of movement. The inevitable result of these factors is multiculturalism and a multicultural society. Multiculturalism is the way in which communities with different cultures come together for various reasons and live within the framework of common values. 
Multiculturalism, which is viewed as a society scheme in which cultural diversity and richness are reflected, is also viewed as a political order in many countries today in order to keep societies together. Multicultural levels of cultural freedoms, where all communities that live together tolerate the values of their lives, are experiencing equality. While there are cultural riches around common values in multicultural societies, harmonization plays an important role in keeping societies together. In this context, in every social structure in which multiculturalism is experienced, translation is a cross-cultural social phenomenon.

Indonesia is multicultural state, sufficiently tolerant, but, any time, ethnic conflicts may appear. Therefore, Indonesia must implement multicultural education continuously focusing on (1) regions, ethnics and traditions; (2) faith; and (3) tolerance. In addition, the state must assure multicultural security for citizens, such as, keeping energy security, economic security and cultural security. Fulfillment of these requirements will assure solution to conflicts, or significantly minimize possibility of conflicts to occur.

The current globalization process does not repel isolative condition at all, nor enable cultural development strangely. In such condition, the only method to prevent cultural conflicts is to implement dialogue between cultures.

Multicultural societies need multi-lingual interpreters who can briefly recognize different cultures in order to be able to sustain their existence, through an agreement that will create awareness of cultural wealth. This is possible with Community Interpretation, which has emerged as a new concept in the field of translation, equipped with every sense.

In addition to helping a community of diverse cultures benefit from public services, community interpreting also plays a role in the persistence of a multicultural society. Besides language knowledge, there is a need for "community interpreters" who recognize different cultural values and which will provide solid support for the lives of the communities in consensus. In any language and culture, people move from the thought of being a social entity; the community interpreters who recognize both languages and cultures should be allowed to work without forgetting their identity and cultural values in the place where their lives will last, and to benefit from all kinds of services on an equal level. In addition, it will be appropriate for community interpreters to provide adaptation training around the common values to be organized, in terms of collecting and adapting to the different cultures.

In this context, the training of community interpreters should be organized according to multicultural society structures. Being multicultural 
at an early age will support the individual to have a humanist structure. Multiculturalism will also contribute to the elimination of different prejudices and the creation of an environment of tolerance for the diversity of life. Multiculturalism will provide opportunities to compare differences to societies and individuals. Thus, the different ones will respect and appreciate events at a healthier level of thought. At the same time, acting from different perspectives will be an opportunity to be protected from conflicts. Multiculturalism will have a peaceful personality thanks to the benefits that the individual offers.

\section{REFERENCES}

\section{Books}

Andersen, R., \& Cusher, K. (1994). Multicultural and intercultural studies. Teaching Studies of Society and Environment, Sydney: Prentice-Hall, 320.

Arı, Sevinç (2014) Translation Sociology, Aylak Adam KültürSanat Publishing, İstanbul.

Carr, Silvana E. 1997. The Critical Link: Interpreters in the Community. Amsterdam; Philadelphia: J. Benjamins.

Doytcheva, Milena (2009) Multiculturalism, İletişim Publishing, İstanbul.

Eruz, Sakine (2010) Multiculturalism and Translation, Multilingual Publishing, İstanbul.

Fleras, A., \& Elliott, J. L. (2002). Engaging diversity: Multiculturalism in Canada (2nd ed.). Nelson Thomson Learning.

Gentile, Adolfo, Ozolins, Uldis, Vasilakakos, Mary. 1996. Liaison Interpreting, A Handbook. Melbourne: Melbourne University Press.

Gürçağlar, Ş. T. (2008). The Politics and Poetics of Translation in Turkey, 1923-1960. BRILL.

Ministry of Education (1999) ÖrnekleriyleTürkçeSözlük, Ministry of Education Publishing: 2799 Science and Culture Series: 772 Dictionary Series:5

Munib, Achmad. 2009. Pengantar Ilmu Pendidikan. Semarang: Unnes Press.

Nida, E. A. (1964). Toward a science of translating: with special reference to principles and procedures involved in Bible translating. Brill Archive.

Parekh, B. (2000). Rethinking multiculturalism: Cultural diversity and political theory. Palgrave.

Roberts, Roda. 2002. Community interpreting: A profession in search of its identity. In Hung, E. (ed.). Teaching Translation and Interpreting 4: Building Bridges. John Benjamins Publishing Company.

\section{Journal Articles}


Banks, J. A. (1993). Multicultural education: Historical development, dimensions, and practice. Review of research in education, 19, 3-49.

Brent, A. (1982). Multicultural education and relativism: A reply to Phillips-Bell. Journal of Philosophy of Education, 16, 125 - 130. https://doi.org/10.1111/j.1467- 9752.1982.tb00604.x

Colombo, E. (2015). Multiculturalism: An overview of multicultural debates in western societies. Current Sociology Review, 63(6), 800824. https://doi.org/10.1177/0011392115586802

Fowers, B. J., \& Davidov, B. J. (2006). The virtue of multiculturalism: Personal transformation, character, and openness to the other. American Psychologist, 61, 581-594. http:/ / dx.doi.org/10.1037/0003-066X.61.6.581

Guo, Y. (2011). Perspectives of immigrant Muslim parents: Advocating for religious diversity in Canadian schools. Multicultural Education, 18, 55-60. https:// files.eric.ed.gov/fulltext/EJ951848.pdf

Jiang, Lihua. 2007. From 'Community Interpreting' to 'Discourse Interpreting': Establishing Some Useful Parameters. EU-High-Level Scientific Conference Series MuTra 2007 - LSP Translation Scenarios: Conference Proceedings. Available at: <http://www.euroconferences.info/proceedings/2007_Proceedings/200 7_Jiang_Lihua.pdf>.

Mikkelson, Holly. 1996b. Community interpreting: An emerging profession. In Interpreting, International journal of research and practice in interpreting, 1996, 1(1), pp.125-129.

Parekh, B. (2001). Rethinking multiculturalism: Cultural diversity and political theory. Ethnicities, 1(1), 109-115.

Shannon-Baker, P. (2018). A multicultural education praxis: Integrating past and present, living theories, and practice. International Journal of Multicultural Education, 20(1), 48-66. https://doi.org/10.18251/ijme.v20i1.1518

Singh, B. R. (1984). Multicultural education: A study of the impact of the CNAA on a B.Ed. degree. Educational Studies, 10, 227-236. https://doi.org/10.1080/0305569840100303 